\title{
The Potential of Natural Propolis Extract Combined with Bovine Bone Graft in Increasing Heat Shock Protein 70 and Osteocalcin on Socket Preservation
}

\author{
Utari Kresnoadi ${ }^{1}$ Retno Pudji Rahayu ${ }^{2}$ Maretaningtias Dwi Ariani ${ }^{3}$ Soesanto Soesanto ${ }^{4}$
}

${ }^{1}$ Department of Prosthodontic, Faculty of Dental Medicine, Universitas Airlangga, Surabaya, Indonesia

2Department of Oral and Maxillofacial Pathology, Faculty of Dental

Medicine, Universitas Airlangga, Surabaya, Indonesia

3 Prosthodontic Department, Faculty of Dental Medicine, Universitas Airlangga, Surabaya, Indonesia

${ }^{4}$ Department of Oral and Maxillofacial Surgery, Faculty of Dental

Medicine, Universitas Airlangga, Surabaya, Indonesia

\begin{abstract}
Address for correspondence Utari Kresnoadi, DDS, MSc, Department of Prosthodontic, Faculty of Dental Medicine, Universitas Airlangga, Mayjen. Prof. Dr Moestopo 47, Surabaya, Indonesia 60132 (e-mail: utari-k@fkg.unair.ac.id).
\end{abstract}

Eur J Dent 2020;14:31-37

Abstract
Keywords
- propolis
- bovine bone graft
- heat shock protein 70
- osteocalcin
- bone regeneration

Objective This study aims to combine natural propolis with bovine bone graft (BBG) as a means of extraction socket preservation after 3 and 7 days toward expression of heat shock protein (HSP) 70 and osteocalcin to regenerate bone.

Materials and Methods The Cavia cobaya were divided into eight groups, each consisting of seven samples. Their lower left incisors were extracted and induced with PEG, propolis extract, BBG, and a combination of propolis extract BBG. The research subjects were terminated on days 3 and 7 postextraction. Immunohistochemical and histopathological examinations were subsequently performed to observe HSP 70 expression, osteocalcin expression, osteoblasts, and osteoclasts.

Statistical Analysis Data obtained were then analyzed with one-way analysis of variance (ANOVA) and Tukey's honestly significant difference (HSD) tests.

Results Both the groups with the combination of propolis extract and BBG on days 3 and 7 were found to present the highest number of HSP70 expression, osteocalcin expression, and osteoblast cells as well as the lowest number of osteoclasts.

Conclusion Both the groups with the combination of propolis extract and BBG on days 3 and 7 were found to present the highest number of HSP70 expression, osteocalcin expression, and osteoblast cells as well as the lowest number of osteoclasts.

\section{Introduction}

When making dentures, removable dentures, fixed dentures, and implant dentures, a strong support bone is required in order that the dentures can perform effectively. Unfortunately, postextraction bone resorption can cause significant problems in the manufacture of dentures. The retention factor preventing the detaching of dentures is strongly influenced by several anatomical factors, particularly that of a prominent ridge. To obtain a promising ridge, resorption usually caused by the extraction of natural teeth needs to be reduced. Consequently, preservation of the extraction socket is required to reduce alveolar bone resorption. Socket preservation is performed by using various kinds of bone replacement material to the extraction socket. The same effort can be made in the edentulous area to increase the aesthetic factor in fix dentures and removable dentures. ${ }^{1,2}$ Similarly, the prerequisites for successful implant therapy include adequate alveolar bone volume and beneficial ridge shape accompanied by appropriate surgical techniques. However, tooth extraction causing alveolar ridge resorption, 
inadequate bone volume, and unfavorable ridge contour for the placement of dental implants remain problems.

In cases where osteoclasts increase, alveolar bone resorption will occur. Under inflammatory conditions, fibroblast tissue stimulates osteoprotegerin to inhibit RANKL binding to RANK and triggers the growth of fibroblast growth factor 2 (GF2). FGF-2 is a growth factor that controls osteoblast cell proliferation and differentiation. FGF2 has mitogenic potential in progenitor cells, which have an important role in bone metabolism and regulation of proliferation and differentiation. ${ }^{3}$ Physiologically, bone is periodically resorbed by osteoclasts while new bone is formed by osteoblasts.

In addition, heat shock protein (HSP)70 is a kind of stress protein emerging in all cell types. Under normal circumstances, HSP acts as a chaperone molecule ${ }^{4}$ is expressed when cells experience stress due to injury and also plays a role in maintaining cell homeostasis. Moreover, intracellular HSP70 acts as an antiinflammatory and enhances cell proliferation, thus supporting its role in wound healing. During inflammation, elevated levels of HSP70 give a cytoprotection by inhibiting the signaling component of the inflammatory pathway, such as the transcription factor NF-к $\beta .{ }^{5}$

Osteocalcin as a marker for bone regeneration has been studied for long time. ${ }^{6,7}$ Osteocalcin is a noncollagen protein that is abundant in bone and is specifically produced by osteoblasts. ${ }^{8,9}$ Osteocalcin as a marker in the process of bone maturation facilitated by three vitamin K-dependent $\gamma$-carboxyglutamic acid residues. ${ }^{10}$

In the fields of medicine and dentistry, graft is frequently employed for bone defect repair and augmentation although its use has yet to produce the expected results. ${ }^{11-16} \mathrm{BBG}$, an allograft manufactured by the tissue bank at Dr. Soetomo Hospital, has been frequently employed.

Furthermore, propolis contains resins and numerous bioactives, such as bioflavonoids, artepillin, apigenin, and caffeic acid phenethyl esters (CAPE), producing inflammatory, antioxidant, antibacterial, antiviral, and immunomodulatory effects which can stimulate tissue healing. ${ }^{17-19}$ This research aimed to preserve tooth extraction sockets through the use of a combination of natural propolis extract and BBG to fill the extraction socket to increase HSP 70 expressions, osteocalcin expressions, and osteoblasts as signs of bone regeneration as well as to decrease resorption of ridge after tooth extraction.

\section{Materials and Methods}

Ethical clearance for this research was issued by the Committee of Health Research Ethics, Faculty of Dental Medicine, Universitas Airlangga No.014/HRECCIODM/III/2018. This research constituted an experimental investigation incorporating a randomized posttest control group design. The subjects consisted of healthy and active male, Cavia cabaya, weighing 300 to $350 \mathrm{~g}$ and aged between 3 and 3.5 months. Those C. cobaya were placed in a cage with adequate air and light flow. The samples were adapted for 5 days to get the good general health and environmental adaptation. The C. cobaya were selected as subjects of this research due to their metabolic and immunological responses, which are similar to those of humans. The subjects were divided into eight groups. Each group consisted of seven C. cabaya. Propolis was extracted from the crude propolis produced by Apis melifera bees found in Lawang, East Java, Indonesia by means of a maceration method. ${ }^{20}$

After the extraction of the teeth form subjects in Groups I and II, the sockets were filled with polyethylene glycol (PEG) as a control; in Groups III and IV, the sockets were filled with BBG + PEG; in Groups V and VI, the sockets were filled with propolis extract + PEG, and in Groups VII and VIII, the sockets were filled with propolis extract + BBG + PEG. The filler of those sockets is explained in - Table 1. The sockets were then sutured. The subjects were sacrificed on day 3 for the Groups I, III, V, and VII and on day 7, for Groups II, IV, VI, and VIII. The specimens were decalcified for 2 months using ethylenediaminetetraacetic acid (EDTA). Immunohistochemical preparations were produced using monoclonal anti-HSP70 antibodies (SC-373867; Santa Cruz Biotechnology, Inc., Dallas, TX) and monoclonal antiosteocalcin antibodies (SC-365797; Santa Cruz Biotechnology, Inc.). Hematoxylin-eosin staining was performed to examine the level of osteoblast and osteoclast. All data were collected and analyzed using an ANOVA test and subsequently, a Tukey's honestly significant difference (HSD) test on SPSS 15.0. The results of this study showed a significant difference with a value of $p<0.05$.

\section{Results}

The number of osteoblasts on days 3 and 7 showed in -Fig. 1. The results of the number of osteoblasts on examination days 3 and 7 are shown in -Fig. 1. Group VIII showed the highest number of osteoblasts, while the lowest number was present in Group I. ANOVA test results showed that there was significant difference in the value of $p=0.000$ $(p<0.05)$.

The number of osteoclasts on days 3 and 7 are shown in -Fig. 2. The number of osteoclasts on days 3 and 7 decreased in all treatment groups. Group I showed the highest number of osteoclasts, while the lowest number was present in Group VIII. The highest number of osteoclasts was found in Group I, while the lowest number was found in Group VIII. ANOVA test results showed that there was significant difference with the value of $p=0.000(p<0.05)$. The microscopic images of osteoblasts and osteoclasts at 400x magnification on day 7 can be seen in - Fig. 3 .

The highest number of HSP70 expression on days 3 and 7 was found in Groups VII and VIII. In contrast, the lowest number of HSP70 expression was present in Groups I and II. The expression of HSP70 on day 7 was also found to be

Table 1 The material composed for each group

\begin{tabular}{|l|l|l|l|}
\hline Group & PEG & Propolis & BBG \\
\hline I and II & $25 \mathrm{~g}$ & - & - \\
\hline III and IV & $24.5 \mathrm{~g}$ & - & $0.5 \mathrm{~g}$ \\
\hline V and VI & $24.5 \mathrm{~g}$ & $0.5 \mathrm{~g}$ & - \\
\hline VII and VIII & $24 \mathrm{~g}$ & $0.5 \mathrm{~g}$ & $0.5 \mathrm{~g}$ \\
\hline
\end{tabular}

Abbreviations: BBG, bone bovine graft; PEG, polyethylene glycol. 
30

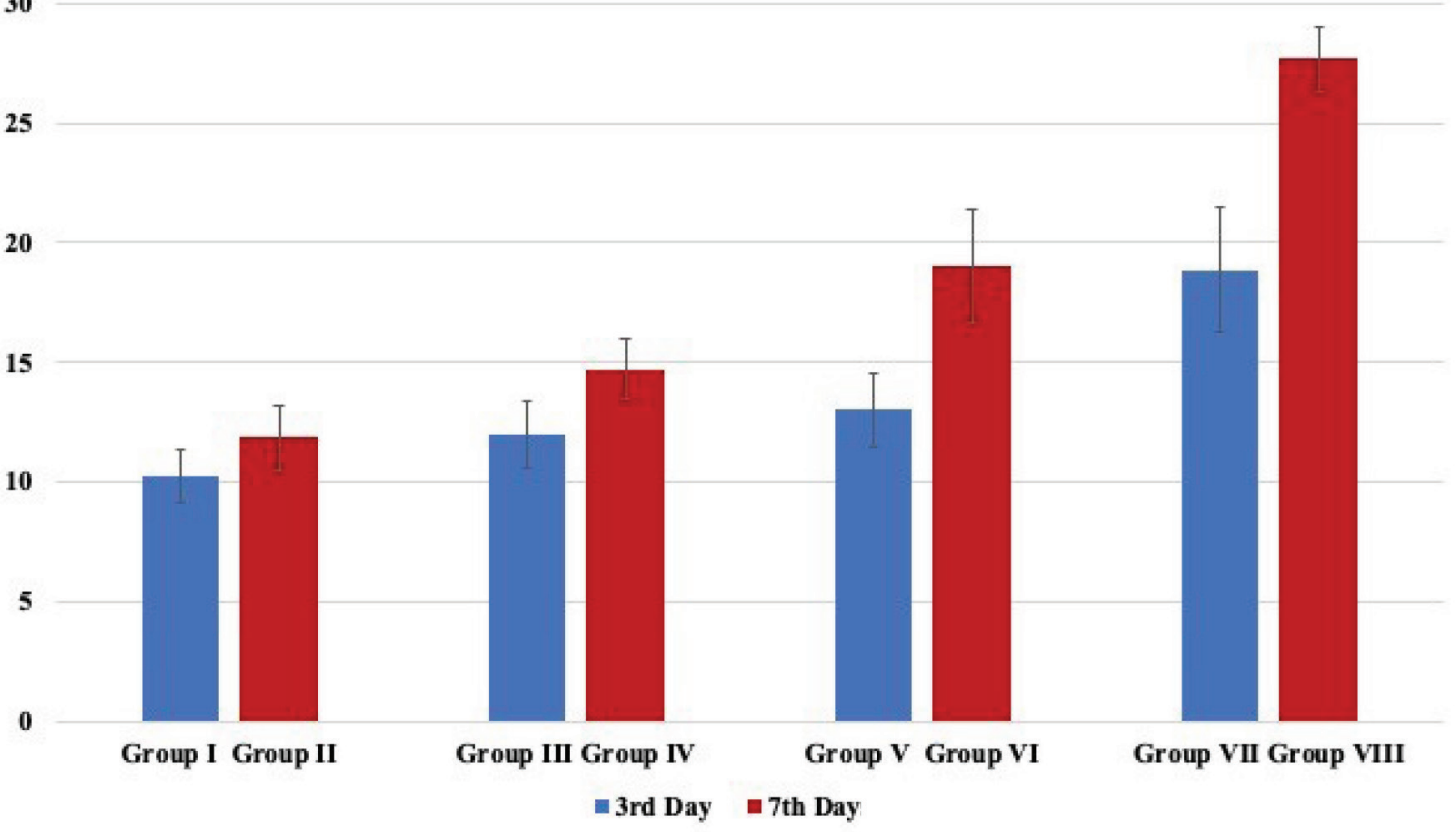

Fig. 1 The bar chart shown the mean and standard deviation of the number of osteoblasts induced by polyethylene (PEG), propolis extract (P) and bone bovine graft (BBG) for each group.

25

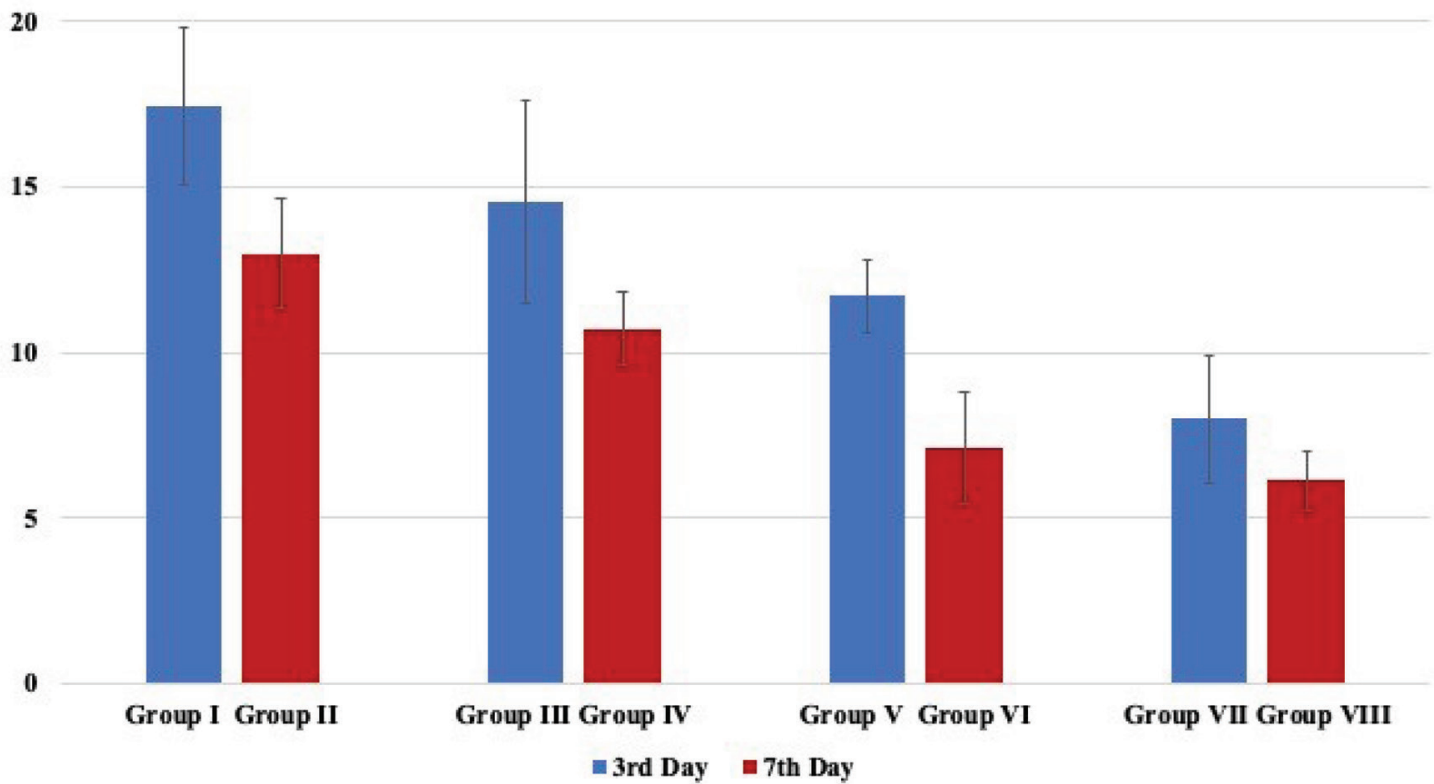

Fig. 2 The bar chart shown the mean and standard deviation of the number of osteoclasts induced by polyethylene (PEG), propolis extract (P) and bone bovine graft (BBG) for each group.

higher than that on day 3 (-Fig. 4). ANOVA test results on HSP70 on days 3 and 7 after the examination indicated that there was significant difference between all groups with the value of $p=0.000(p<0.05)$. The Tukey's HSD test was performed on HSP70 expression on days 3 and 7 and shown in - Table 2 . 

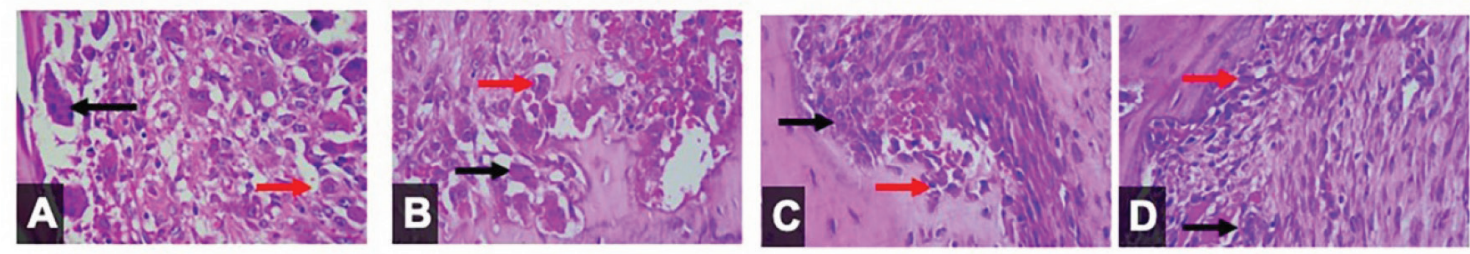

Fig. 3 The microscopic image of osteoblast (red arrows) and osteoclast (black arrows) in day 7 induced with polyethyl glycol (PEG) (A), propolis extract (B), bovine bone graft $(\mathbf{C})$ and combination of propolis extract and bovine bone graft (D).

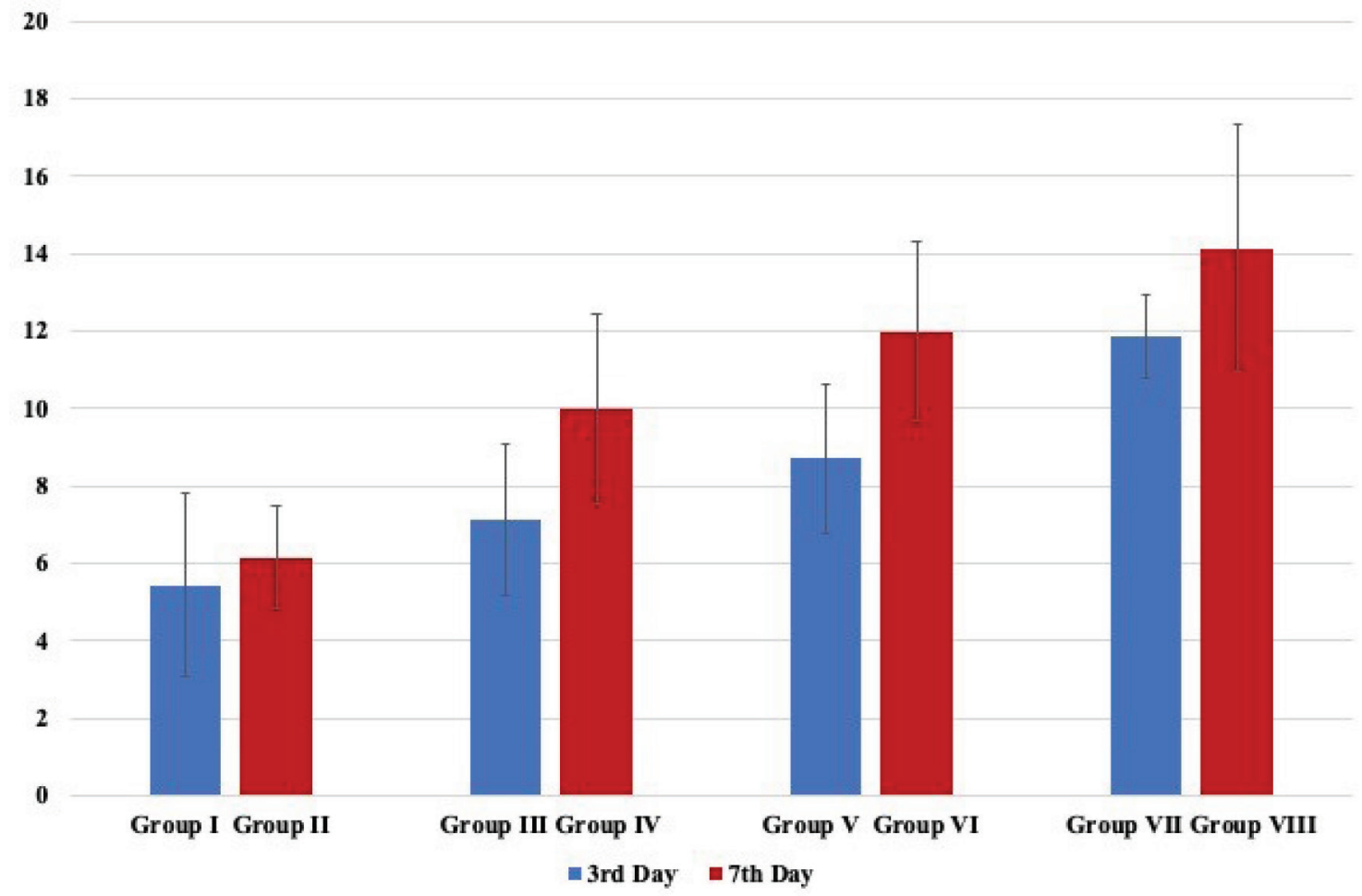

Fig. 4 The bar chart shown the mean and standard deviation of the expression of HSP70 induced by polyethylene (PEG), propolis extract (P) and bone bovine graft (BBG) for each group.

The highest number of osteocalcin expression on days 3 and 7 was found in Groups VII and VIII. Meanwhile, the lowest number of osteocalcin expression was in the Groups I and II. Besides, the number of osteocalcin in expression on day 7 was known to be higher than that on day 3 ( - Fig. 5). ANOVA test showed that there was a significant difference in the expression of osteocalcin among all groups by the $p$ value $0.000(p<0.05)$. The Tukey's HSD test was performed. The results of Tukey's HSD test on osteocalcin expression on days 3 and 7 are shown in - Table 3. The microscopic images of HSP70 and osteocalcin expression on day 7 can be seen in - Fig. 6 .

\section{Discussion}

Propolis has antioxidant properties inhibiting reactive oxygen species (ROS), a free radical that plays a role in bone resorption and the osteoclastogenesis processes generated by active osteoclasts. ROS can also stimulate a phosphorylation process from inhibitor kappa $\beta$ (Ік $\beta$ ) which function to bind NF-KB ensuring that it remains inactive in the cytoplasm. If the Iк $\beta$ is phosphorylated, then Iк $\beta$ and NF-кB are released. Thus, NF-KB becomes active and moves to the cell nucleus, a process referred to as NF-KB activation. The presence of flavonoids in propolis can inhibit ROS formation, so that NF-KB activation will also be inhibited. ${ }^{21}$ In this research, it was proved that the combination of propolis extract and BBG can increase intracellular HSP70 expression. This can occur because propolis extract contains polyphenol compounds which have antioxidant, cytoprotective, and anti-inflammatory effects. Polyphenols are phytochemicals that are widely available from foods derived from plants. Increased intake of polyphenols protects against disease because they have antiinflammatory and vascular protective effects. $^{22}$

Polyphenol is also known to be capable of capturing free radicals produced by oxidative stress. Polyphenols are able to inhibit cell injury, oxidative stress, and swelling, while increasing the response of cytoprotective. Antioxidant effects can inhibit ROS generation and neutralize intracellular redox potential. ROS can be produced in the wound area and in this 
Table 2 Multiple comparison of on heat shock protein 70 expressions in all group using Tukey's honestly significant difference

\begin{tabular}{|c|c|c|c|c|c|c|c|c|}
\hline Group & I & II & III & IV & $\mathrm{V}$ & VI & VII & VIII \\
\hline 1 & & $0.000^{\mathrm{a}}$ & $0.001^{a}$ & $0.000^{\mathrm{a}}$ & & & & \\
\hline II & & & 0.427 & 0.357 & & & & \\
\hline III & & & & $0.000^{\mathrm{a}}$ & & & & \\
\hline \multicolumn{9}{|l|}{ IV } \\
\hline V & & & & & & 0.065 & $0.002^{\mathrm{a}}$ & $0.000^{a}$ \\
\hline $\mathrm{VI}$ & & & & & & & 0.433 & $0.020^{\mathrm{a}}$ \\
\hline VII & & & & & & & & 0.347 \\
\hline VIII & & & & & & & & \\
\hline
\end{tabular}

andicates a significant difference between groups $(p<0.05)$.

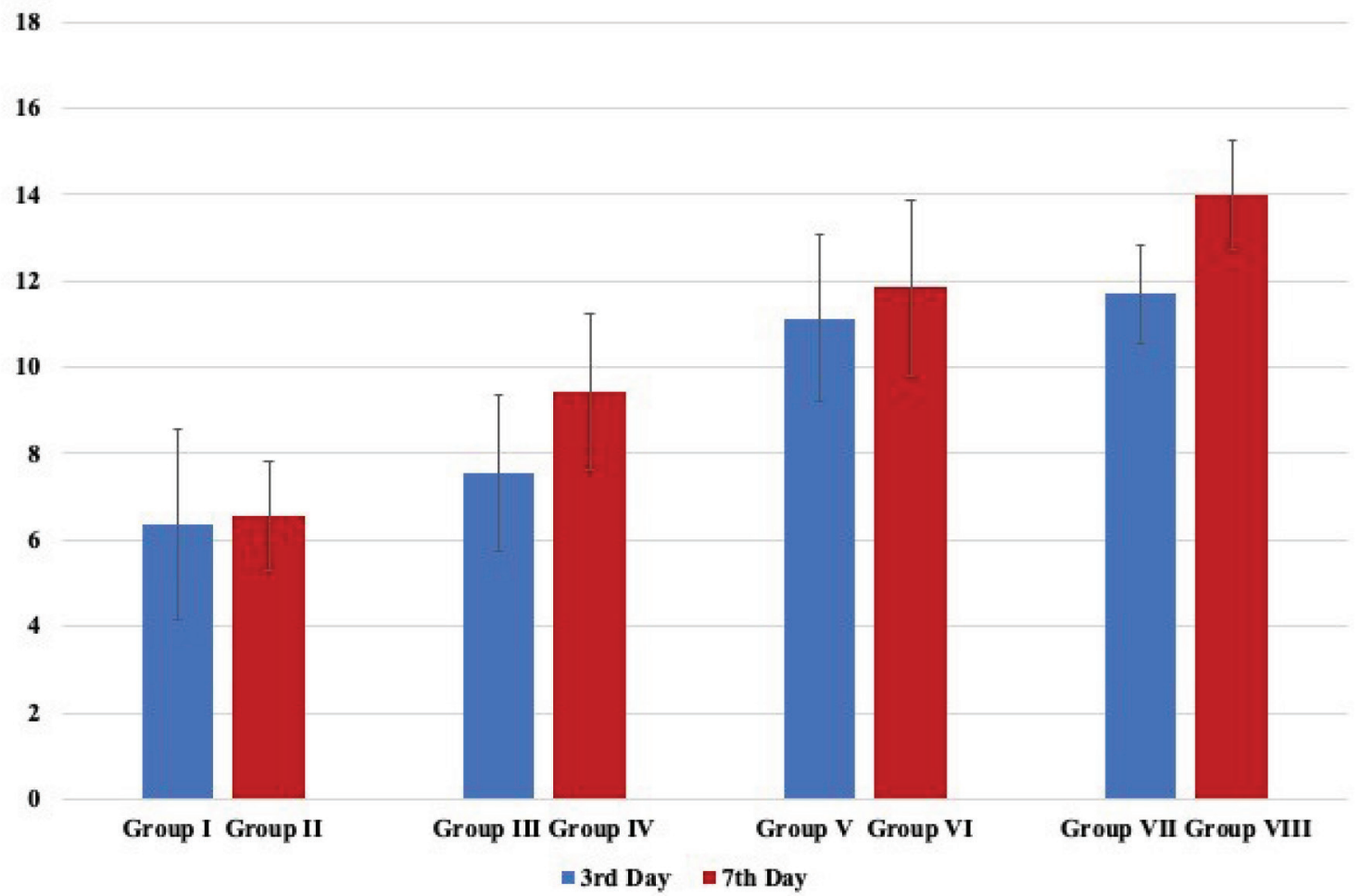

Fig. 5 The bar chart shown the mean and standard deviation of the expression of osteocalcin induced by polyethylene glycol (PEG), Propolis extract $(P)$ and bone bovine graft (BBG) for each group.

case the extraction socket. The appearance of ROS is actually normal and, in certain circumstances, it can also be considered a sign of the initiation of the wound-healing process. However, at high levels, ROS can damage the structural elements of the cell membrane. ROS will activate the p38 MAPK cascade signal, kinase, which is activated by stress and associated with HSP gene transcription. The p38 MAPK activated will then phosphorylate HSF on cells. ${ }^{22}$

HSP70 is known to have capabilities that induce activities in a cell repair system and consequently is referred to as a cellular stress response. ${ }^{23}$ This signifies that an increase in HSP70 will protect proteins, including protection of the expression cells themselves. This will then further enhance cell function including that of immune system cells. ${ }^{24}$ In addition, HSP70 activities in wound healing are also mediated by macrophages by increasing regulation of phagocyte function and inducing macrophages to release cytokine and growth factors. ${ }^{25}$

Similarly, previous research conducted by Somsanith et $\mathrm{a}^{26}$ also posited that a propolis and $\mathrm{TiO} 2$ nanotubes combination in dental implants can increase the osseointegration. In studies with Masson's trichrome staining used to distinguish collagen fibers from muscle tissue on biological slides showed expression of well-formed collagen to form bone on PL-TNT-Ti. While immunohistochemical staining showed that morphogenetic bone protein BMP2 and BMP 7 around PL-TNT-Ti increased expression of collagen fibers and 
Table 3 Multiple comparison of on osteocalcin expressions in all group using Tukey's honestly significant difference

\begin{tabular}{|c|c|c|c|c|c|c|c|c|}
\hline Group & I & II & III & IV & V & VI & VII & VIII \\
\hline 1 & & 0.796 & $0.002^{\mathrm{a}}$ & $0.000^{\mathrm{a}}$ & & & & \\
\hline II & & & $0.016^{\mathrm{a}}$ & $0.004^{\mathrm{a}}$ & & & & \\
\hline III & & & & 0.052 & & & & \\
\hline \multicolumn{9}{|l|}{ IV } \\
\hline V & & & & & & $0.024^{a}$ & $0.035^{a}$ & $0.016^{a}$ \\
\hline $\mathrm{VI}$ & & & & & & & 0.088 & $0.004^{\mathrm{a}}$ \\
\hline VII & & & & & & & & 0.154 \\
\hline VIII & & & & & & & & \\
\hline
\end{tabular}

andicates a significant difference between groups $(p<0.05)$.

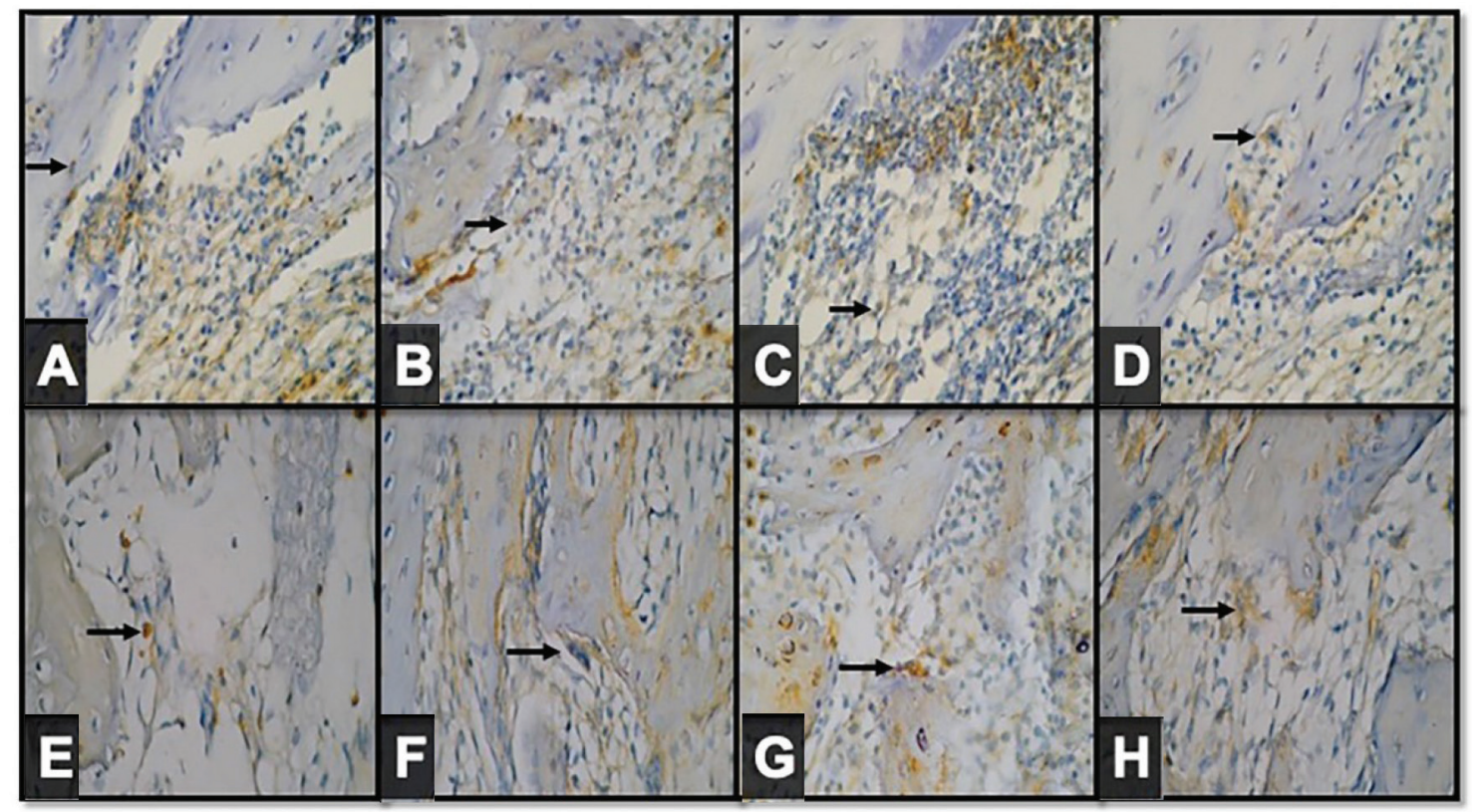

Fig. 6 The microscopic image of the expression of HSP70 induced (arrows) with PEG (A), Propolis extract (B), bovine bone graft (C) and combination of propolis extract and bovine bone graft (D) and osteocalcin induced with polyethylene glycol (PEG) (E), Propolis extract (F), bovine bone graft $(\mathbf{G})$ and combination of propolis extract and bovine bone graft $(\mathbf{H})$ on day 7 .

osteogenic differentiation, whereas expression of inflammatory cytokines interleukin- $1 \beta$ and tumor necrosis factor- $\alpha$ decreased. ${ }^{27}$

Propolis, according to Wieckiewicz et al, ${ }^{28}$ contains resins (40-55\%), bees wax, and fatty acids (20-35\%), aromatic oils $(\sim 10 \%)$, pollen $(\sim 5 \%)$, other components such as amino acids, minerals, vitamins (vitamin $A$, vitamin $B$ complex, and vitamin $E$ ) as well as high active biochemical substances; namely, bioflavonoids (vitamin P), phenols, and aromatic components. The biological activities of propolis are related to flavonoids and hydroxycinnamic acid derivatives. Flavonoids are plant metabolites that are beneficial to health through cell signaling pathways and have antioxidant effects. Flavonoid molecules are found in fruits and vegetables. Water-soluble flavonoids and polyphenolic molecules have 15 carbon atoms. Flavonoids have biological effects because of their ability to modulate the cell signaling cascade. Flavonoids have anti-inflammatory, antithrombogenic, antidiabetic, anticancer, and neural-protective activities through in vitro mechanisms and in vivo experiments.

The combination of extracts of natural propolis and BBG to preserve tooth extraction sockets can reduce inflammation, increase HSP 70 and reduce osteoclast, and accelerate osseointegration, thereby accelerating the growth in expression of osteocalcin, which is the largest element within osteoblast cells.

\section{Conclusion}

The combination of natural propolis extract and BBG can increase HSP70 expression, osteocalcin expression, and osteoblasts but decreases the number of osteoclasts. 


\section{Funding}

The authors gratefully acknowledge the financial support provided by the Rector for Research Funding of Airlangga University, managed by the Community Research and Service Institute, Airlangga University, as an Excellent Research Institution of Higher Education No. 893/UN3/ 2018.

\section{Conflict of Interest}

None declared.

\section{References}

1 Darby I, Chen S, De Poi R. Ridge preservation: what is it and when should it be considered. Aust Dent J 2008;53(1):11-21

2 Das S, Jhingran R, Bains VK, Madan R, Srivastava R, Rizvi I. Socket preservation by beta-tri-calcium phosphate with collagen compared to platelet-rich fibrin: a clinico-radiographic study. Eur J Dent 2016;10(2):264-276

3 Yoshida T, Sakamoto A, Tsukamoto N, Nakayama K, Iwamoto Y. Establishment of an animal model of a pasteurized bone graft, with a preliminary analysis of muscle coverage or FGF-2 administration to the graft. J Orthop Surg Res 2009;4(31):31

4 Gowda NKC, Kandasamy G, Froehlich MS, Dohmen RJ, Andréasson C. Hsp70 nucleotide exchange factor Fes1 is essential for ubiquitin-dependent degradation of misfolded cytosolic proteins. Proc Natl Acad Sci U S A 2013;110(15):5975-5980

5 Ferat-Osorio E, Sánchez-Anaya A, Gutiérrez-Mendoza M, et al. Heat shock protein 70 down-regulates the production of toll-like receptor-induced pro-inflammatory cytokines by a heat shock factor-1/constitutive heat shock element-binding factor-dependent mechanism. J Inflamm (Lond) 2014;11(19):19

6 Nugraha AP, Narmada IB, Ernawati DS, et al. Bone alkaline phosphatase and osteocalcin expression of rat's Gingival mesenchymal stem cells cultured in platelet-rich fibrin for bone remodeling (in vitro study). Eur J Dent 2018;12(4):566-573

7 Hendrijantini N, Hartono P, Ari MDA, Rantan FA. Human umbilical cord mesenchymal stem-cell therapy to increase the density of osteoporotic mandibular bone. Eur J Dent 2019;13(1):58-63

8 Akbari S, Rasouli-Ghahroudi AA. Vitamin K and bone metabolism: a review of the latest evidence in preclinical studies. Bio Med Res Inter 2018;1:1

9 Blair HC, Larrouture QC, Li Y, et al. Osteoblast differentiation and bone matrix formation in vivo and in vitro. Tissue Eng Part B Rev 2017;23(3):268-280

10 Rathore B, Singh M, Kumar V, Misra A. Osteocalcin: an emerging biomarker for bone turnover. Int J Res Med Sci 2016;4:3670-3674

11 Lieberman JR, Friedlaender GE. Bone Regeneration and Repair. 1st ed. Totowa, NJ: Humana Press; 2005

12 Boix D, Weiss P, Gauthier O, et al. Injectable bone substitute to preserve alveolar ridge resorption after tooth extraction: a study in dog. J Mater Sci Mater Med 2006;17(11):1145-1152
13 Steigmann M. A bovine-bone mineral block for the treatment of severe ridge deficiencies in the anterior region: a clinical case report. Int J Oral Maxillofac Implants 2008;23(1):123-128

14 Barone A, Aldini NN, Fini M, Giardino R, Calvo Guirado JL, Covani U. Xenograft versus extraction alone for ridge preservation after tooth removal: a clinical and histomorphometric study. J Periodontol 2008;79(8):1370-1377

15 Mardas N, Chadha V, Donos N. Alveolar ridge preservation with guided bone regeneration and a synthetic bone substitute or a bovine-derived xenograft: a randomized, controlled clinical trial. Clin Oral Implants Res 2010;21(7):688-698

16 Pelegrine AA, da Costa CE, Correa ME, Marques JFC Jr. Clinical and histomorphometric evaluation of extraction sockets treated with an autologous bone marrow graft. Clin Oral Implants Res 2010;21(5):535-542

17 Karticioglu H, Mercan N. Antimicrobial activity and chemical composition of Turkish propolis from different region. Afr J Biotechnol 2006;5(11):1151-1153

18 Widjiastuti I, Suardita K, Saraswati W. The expressions of NF-kb and TGFb-1 on odontoblast-like cells of human dental pulp injected with propolis extracts. Dent. J. Majalah. Kedokteran. Gigi. 2014;47(1):13-18

19 Ercan N, Erdemir EO, Ozkan SY, Hendek MK. The comparative effect of propolis in two different vehicles; mouthwash and chewing-gum on plaque accumulation and gingival inflammation. Eur J Dent 2015;9(2):272-276

20 Yuanita T, Zubaidah N, Kunarti S. Expression of osteoprotegrin and osteocalcin level in chronic apical periodontitis induced with east java propolis extract. Iran Endod J 2018;13(1):42-46

21 Perkasa MIA, Yogyarti S, Harijanto E. Propolis extract gel application to the socket of Cavia Cobaya afetr tooth extraction to the quantity of osteoclast. Mater. Dent. J. 2017;8(1):23-28

22 Shapiro H, Singer P, Halpern Z, Bruck R. Polyphenols in the treatment of inflammatory bowel disease and acute pancreatitis. Gut 2007;56(3):426-435

23 Clark MS, Peck LS. Triggers of the HSP70 stress response: environmental responses and laboratory manipulation in an Antarctic marine invertebrate (Nacella concinna). Cell Stress Chaperones 2009;14(6):649-660

24 Soeprijanto B, Assegaf JH. Mechanism of increasing of HSP-70 on Irradiated rat breast cancer due to application of extract of phyllanthus nir. Indonesian. Vet J 2014;15(3):330-336

25 Kovalchin JT, Wang R, Wagh MS, Azoulay J, Sanders M, Chandawarkar RY. In vivo delivery of heat shock protein 70 accelerates wound healing by up-regulating macrophage-mediated phagocytosis. Wound Repair Regen 2006;14(2):129-137

26 Somsanith N, Kim YK, Jang YS, et al. Enhancing of osseointegration with propolis-loaded $\mathrm{TiO} 2$ nanotubes in rat mandible for dental implants. Mater. 2018;11:2-15

27 Khurshid Z, Naseem M, Zafar MS, Najeeb S, Zohaib S. Propolis: a natural biomaterial for dental and oral healthcare. J Dent Res Dent Clin Dent Prospect 2017;11(4):265-274

28 Wieckiewicz W, Miernik M, Wieckiewicz M, Morawiec T. Does propolis help to maintain oral health? Evidence-based. complement. alternative. Med. 2013;1:1-8 